\title{
Microstructure Evolution and Surface Cracking Behavior of Superheavy Forgings during Hot Forging
}

\author{
Zhenhua Wang $\mathbb{D D}^{1,2,3}$ Hongpeng Xue $\mathbb{D D}^{1}$ and Deli Zhao $\mathbb{i D}^{4}$ \\ ${ }^{1}$ School of Mechanical Engineering, Yanshan University, Qinhuangdao 066004, China \\ ${ }^{2}$ State Key Laboratory of Metastable Materials Science and Technology, Yanshan University, Qinhuangdao 066004, China \\ ${ }^{3}$ Hebei Iron \& Steel Technology Research Institute, Shijiazhuang 050023, China \\ ${ }^{4}$ China First Heavy Industries, Qiqihar 161042, China
}

Correspondence should be addressed to Zhenhua Wang; wangzhenhua@ysu.edu.cn

Received 1 August 2017; Revised 30 November 2017; Accepted 4 December 2017; Published 30 January 2018

Academic Editor: Francesco Ruffino

Copyright ( 2018 Zhenhua Wang et al. This is an open access article distributed under the Creative Commons Attribution License, which permits unrestricted use, distribution, and reproduction in any medium, provided the original work is properly cited.

\begin{abstract}
In recent years, superheavy forgings that are manufactured from $600 \mathrm{t}$ grade ingots have been applied in the latest generation of nuclear power plants to provide good safety. However, component production is pushing the limits of the current free-forging industry. Large initial grain sizes and a low strain rate are the main factors that contribute to the deformation of superheavy forgings during forging. In this study, $18 \mathrm{Mn} 18 \mathrm{Cr} 0.6 \mathrm{~N}$ steel with a coarse grain structure was selected as a model material. Hot compression and hot tension tests were conducted at a strain rate of $10^{-4} \cdot \mathrm{s}^{-1}$. The essential nucleation mechanism of the dynamic recrystallization involved low-angle grain boundary formation and subgrain rotation, which was independent of the original highangle grain boundary bulging and the presence of twins. Twins were formed during the growth of dynamic recrystallization grains. The grain refinement was not obvious at $1150^{\circ} \mathrm{C}$. A lowering of the deformation temperature to $1050^{\circ} \mathrm{C}$ resulted in a fine grain structure; however, the stress increased significantly. Crack-propagation paths included high-angle grain boundaries, twin boundaries, and the insides of grains, in that order. For superheavy forging, the ingot should have a larger height and a smaller diameter.
\end{abstract}

\section{Introduction}

In recent years, a large number of superheavy forgings have been manufactured and applied in the construction of the latest generation of nuclear power plants, as nozzle shells, the upper head of reactor pressure vessels, and monoblock lowpressure rotors [1]. In the past, these components were manufactured by welding together small forged parts. Superheavy forging allows for the use of integrated advanced designs. Because no complex welding processes exist, the manufacturing cycle of the nuclear reactor pressure vessels is reduced significantly [2], and the safety and service life of nuclear power plants are improved. The largest available ingots, that is, 600-ton grade ingots, are required to manufacture superheavy forgings [3]. The melting, casting, and forging of 600-ton grade ingots has pushed the limits of current heavy industry; the manufacture of superheavy forgings is termed "extreme manufacturing" [3, 4]. With developments in the energy industry, the forging size is likely to increase in the future [1]. However, the microstructure evolution and surface cracking behavior of superheavy forgings have not been investigated widely. The dynamic recrystallization (DRX) and cracking mechanisms have yet to be elucidated.

The main difficulty in forging superheavy forgings is the huge deformation resistance; in the forging process, alloy steel with a large grain size is deformed at a very low strain rate. During production, approximately $3000 \mathrm{~s}$ is required to complete a $30 \%$ reduction while hot forging a $600 \mathrm{t}$ grade ingot using a $150 \mathrm{MN}$ hydraulic press. The true strain rate was approximately $10^{-4} \cdot \mathrm{s}^{-1}$. This strain rate is far below that used, in general, in hot forging [5]. Typically, strain rates that 


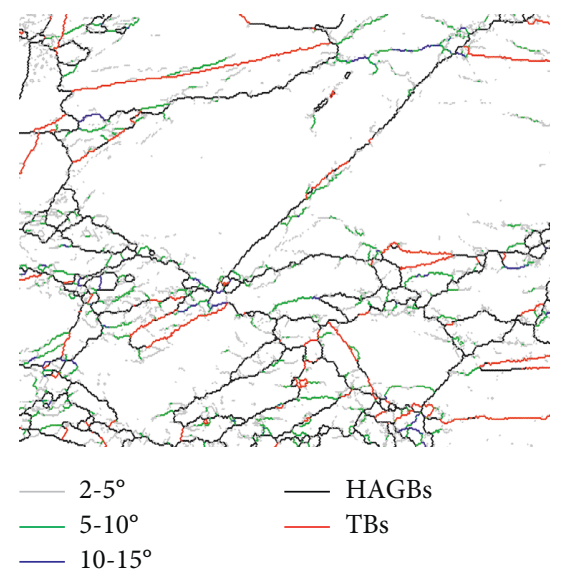

(a)
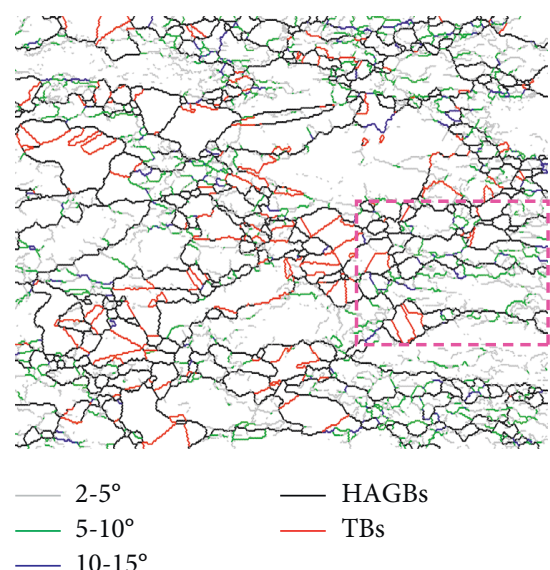

(c)

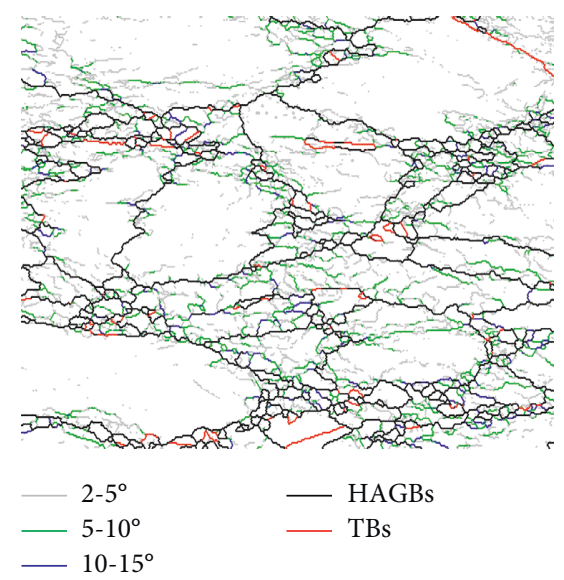

(b)

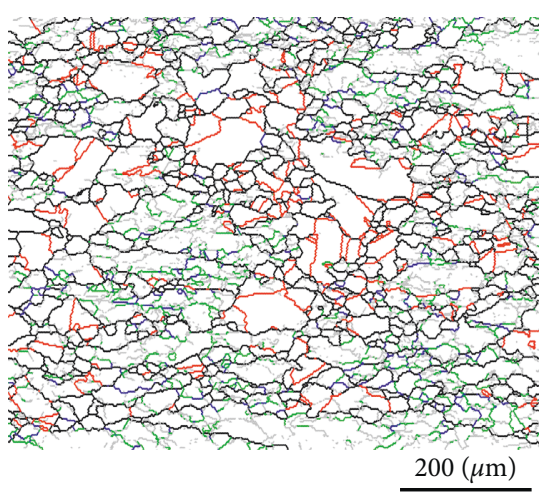

$-2-5^{\circ}$

- $10-15^{\circ}$

(d)

Figure 1: Microstructure of $18 \mathrm{Mn} 18 \mathrm{Cr} 0.6 \mathrm{~N}$ steel compressed at $1050^{\circ} \mathrm{C}$ and $10^{-4} \cdot \mathrm{s}^{-1}$ to different strains (vertical direction is the compression axis). (a) 0.2 , (b) 0.4 , (c) 0.6 , and (d) 0.8 .

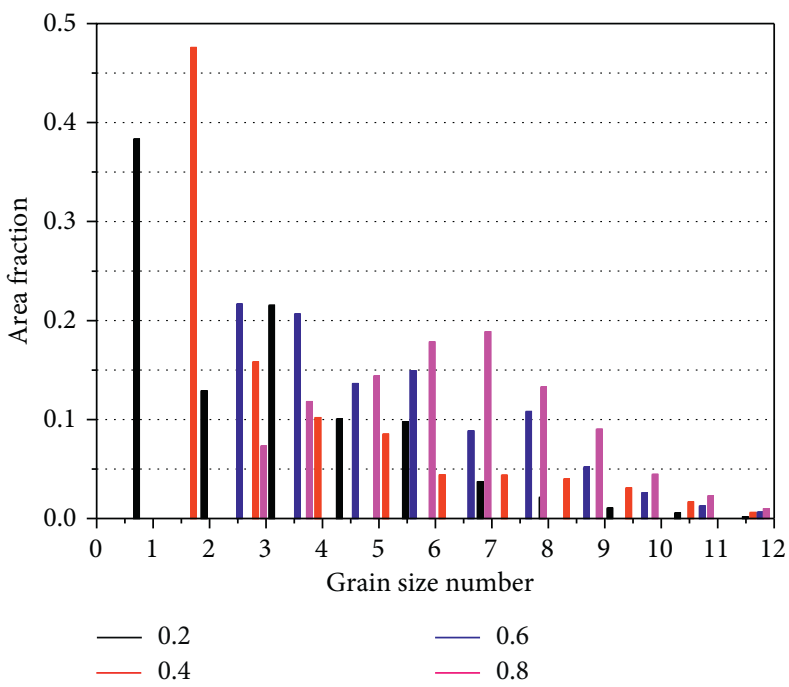

FIgURE 2: Area fractions of different sizes of grains for specimens deformed at $1050^{\circ} \mathrm{C}$ and $10^{-4} \cdot \mathrm{s}^{-1}$. 


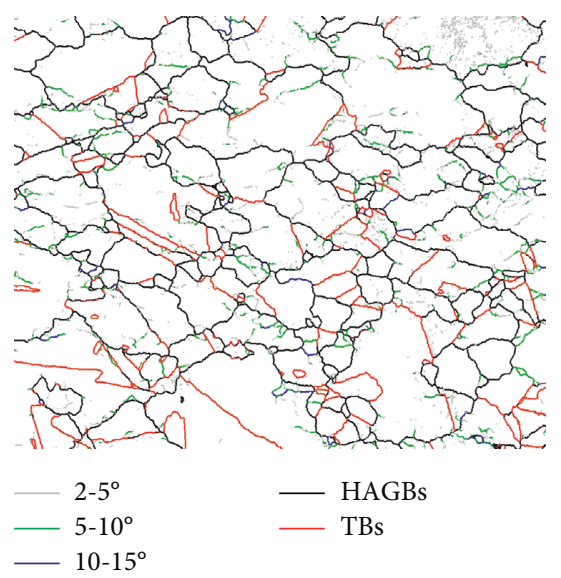

(a)

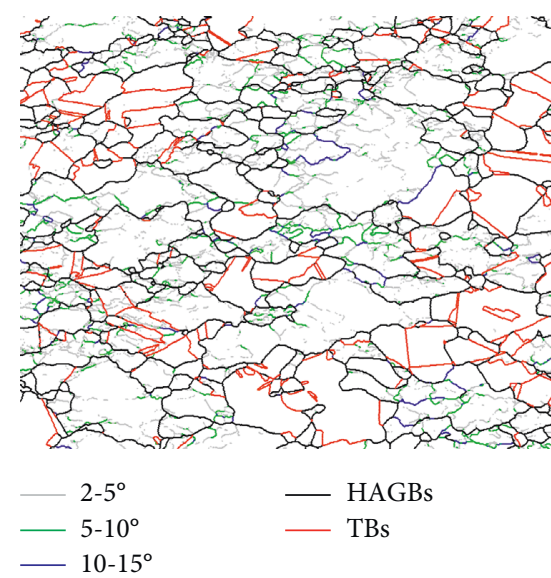

(c)

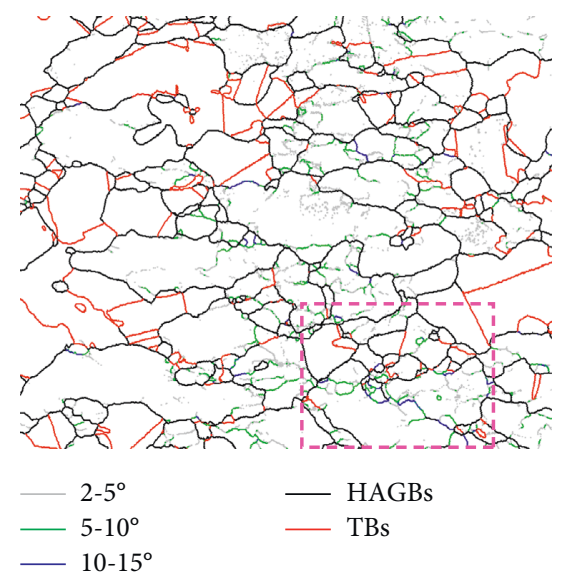

(b)

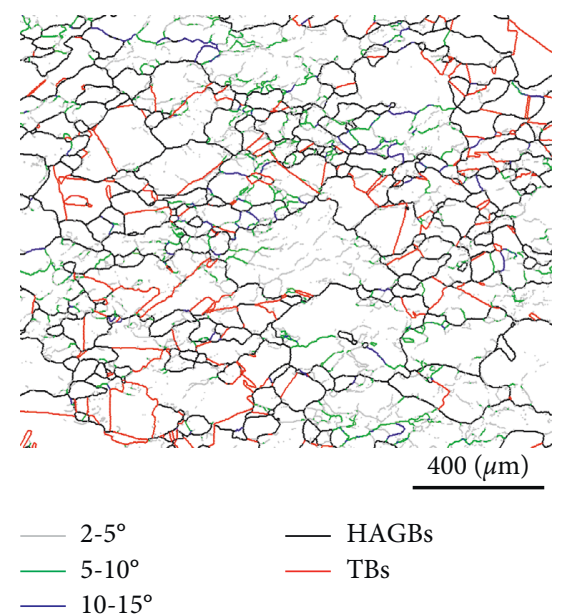

(d)

Figure 3: Microstructure of $18 \mathrm{Mn} 18 \mathrm{Cr} 0.6 \mathrm{~N}$ steel compressed at $1150^{\circ} \mathrm{C}$ and $10^{-4} \cdot \mathrm{s}^{-1}$ to different strains. (a) 0.2 , (b) 0.4 , (c) 0.6 , and (d) 0.8 .

are selected in investigations of hot deformation and cracking behaviors of heavy forgings range from 0.001 to $10 \mathrm{~s}^{-1}$, including those for ultra-supercritical rotors $[6,7]$, main pipes in nuclear plants $[8,9]$, and rollers $[10,11]$. Deformation at very low strain rates features varied and complex recrystallization mechanisms $[12,13]$ and cracking behaviors [14]. The lack of basic data on the microstructure evolution and cracking behavior of superheavy forgings limits their manufacture, development, and applications.

In this study, $18 \mathrm{Mn} 18 \mathrm{Cr} 0.6 \mathrm{~N}$ steel, with a coarse grain structure, was selected as a model material. After hot compression and hot tension at a strain rate of $10^{-4} \cdot \mathrm{s}^{-1}$, the deformed steel microstructure was observed. The DRX and cracking mechanisms were analyzed. Finally, recommendations are provided for ingot shape, forging process, and forging equipment to provide a preliminary basis to optimize the manufacture of superheavy forgings.

\section{Materials and Methods}

The investigated $18 \mathrm{Mn} 18 \mathrm{Cr} 0.6 \mathrm{~N}$ steel was melted in a vacuum electric furnace and then electroslag remelted. The chemical composition of the steel was (wt.\%) $0.084 \mathrm{C}, 17.9$ $\mathrm{Mn}, 18.06 \mathrm{Cr}, 0.62 \mathrm{~N}, 0.46 \mathrm{Si}, 0.2 \mathrm{Ni}, 0.009 \mathrm{P}$, and $0.002 \mathrm{~S}$, and the balance was Fe. Small slabs were cut from the ingot and rolled at $1100^{\circ} \mathrm{C}$. The total true strain during rolling was $\sim 2$. The rolled slabs were heat treated at $1200^{\circ} \mathrm{C}$ for $3 \mathrm{~h}$ to obtain an average grain size of $305 \mu \mathrm{m}$. The ASTM grain size number was 0.5 .

Compression tests were conducted on a Gleeble 3800 simulator. Specimens (diameter: $10 \mathrm{~mm}$; length: $18 \mathrm{~mm}$ ) were heated to $1050^{\circ} \mathrm{C}$ and $1150^{\circ} \mathrm{C}$ and then compressed to true strains of $0.2,0.4,0.6$, and 0.8 at a constant strain rate of $10^{-4} \cdot \mathrm{s}^{-1}$. The hot deformed microstructure was frozen by water cooling. Tensile test was conducted on a MTS810 electrohydraulic servo machine. Specimens (diameter: $10 \mathrm{~mm}$; gauge length: $50 \mathrm{~mm}$ ) were tensioned to fracture at $1050^{\circ} \mathrm{C}$ and $10^{-4} \cdot \mathrm{s}^{-1}$.

Compressed specimens were sectioned parallel to the compression direction. After polishing with a chemomechanical slurry of colloidal silica $(0.02 \mu \mathrm{m})$, the microstructure was observed through electron backscatter diffraction (EBSD) analysis in a Hitachi S-3400 scanning electron microscope (SEM) with TSL-OIM-Analysis software. The spatial 


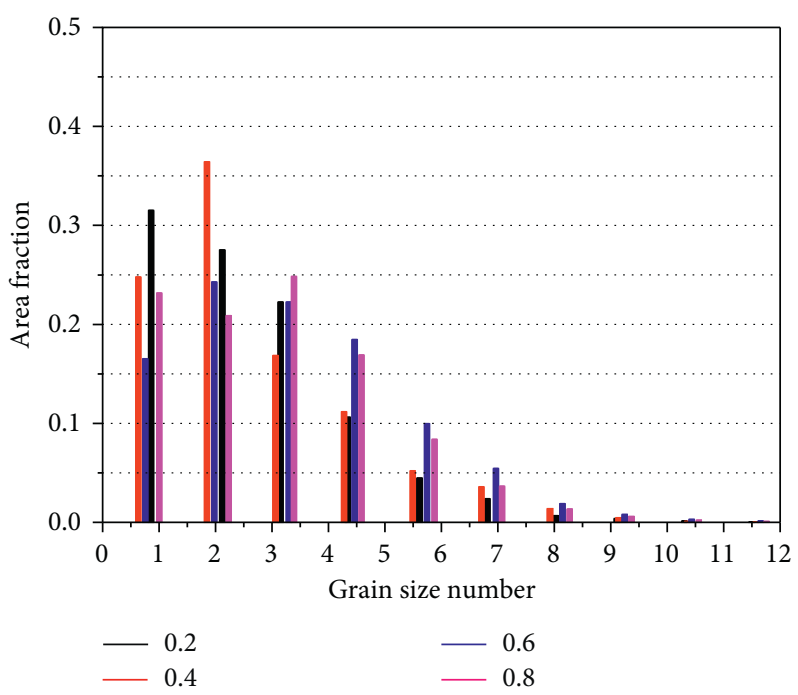

FIgURE 4: Area fractions of different sizes of grains for specimens deformed at $1150^{\circ} \mathrm{C}$ and $10^{-4} \cdot \mathrm{s}^{-1}$.

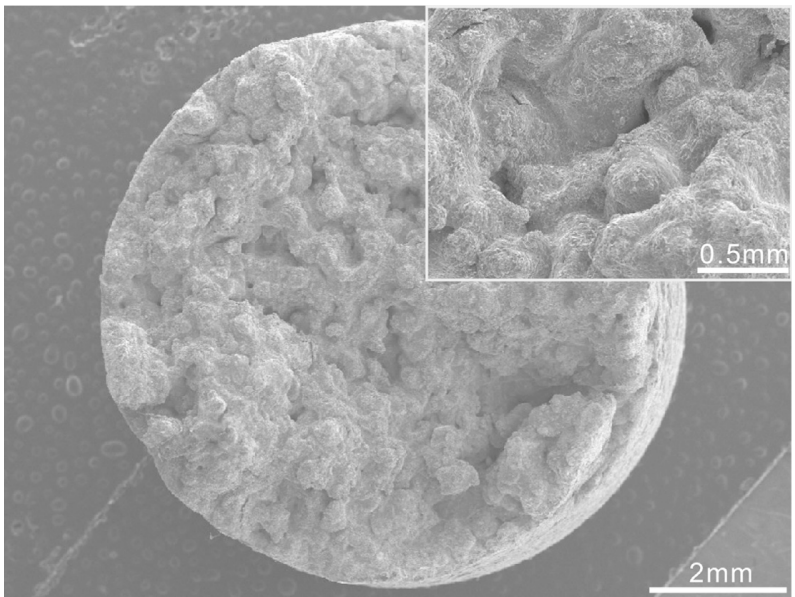

FIGURE 5: Fracture surface of a specimen after tension at $1050^{\circ} \mathrm{C}$ and $10^{-4} \cdot \mathrm{s}^{-1}$.

resolution was $2 \mu \mathrm{m}$, and the misorientation detection limit was $1^{\circ}$. The crystal orientation maps indicated high-angle grain boundaries (HAGBs; misorientations $\geq 15^{\circ}$, shown as black lines), twin boundaries (TBs; shown as red lines), and lowangle grain boundaries (LAGBs; $2^{\circ} \leq$ misorientations $<5^{\circ}$, shown as grey lines; $5 \leq$ misorientations $<10^{\circ}$, shown as green lines; and $10^{\circ} \leq$ misorientations $<15^{\circ}$, shown as blue lines). Additional transmission electron microscopy (TEM) tests were conducted using a JEM-2010 instrument to examine the dislocations and subgrain boundaries.

Tensioned specimens were sectioned parallel to the tension direction. The microstructure near the fracture surface was studied by EBSD. Points with confidence indices lower than 0.1 were filtered and shaded black. Cracks typically exhibited low confidence indices.

\section{Results}

3.1. Deformed Microstructure. The microstructure of $18 \mathrm{Mn} 18 \mathrm{Cr} 0.6 \mathrm{~N}$ steel that was compressed at $1050^{\circ} \mathrm{C}$ and
$10^{-4} \cdot \mathrm{s}^{-1}$ to strains of $0.2-0.8$ is shown in Figure 1 . In the 0.2 reduction specimen (Figure 1(a)), the HAGBs were serrated with some LAGBs appearing nearby. Very few LAGBs were observed inside the grains. Owing to the deformation, some segments of the TBs changed into common HAGBs. In the 0.4 reduction specimen (Figure $1(\mathrm{~b})$ ), parent grains were elongated with some fine DRX grains formed alongside. This kind of structure is termed "necklace DRX" [15]. At the recrystallization front, LAGBs rather than TBs existed, and the density of the LAGBs decreased towards the inside of the grains. This means that the nucleation mechanism of DRX was accompanied by an evolution of LAGBs [16]. As the strain increased, the fraction of recrystallized matrix increased (Figures 1(c) and 1(d)). Some DRX grains grew to a large size (50-200 $\mu \mathrm{m})$, and twins formed in them. However, TBs rarely appeared in the fine new DRX grains $(10-50 \mu \mathrm{m})$. It is clear that twins were formed during the growth of the DRX grains, that is, the migration of HAGBs. The recrystallized and nonrecrystallized regions could be distinguished easily by the 


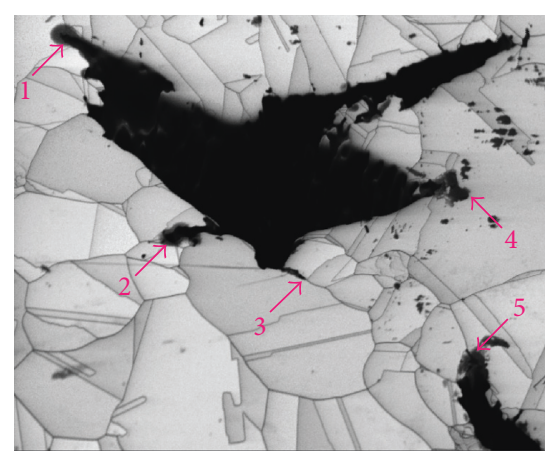

(a)

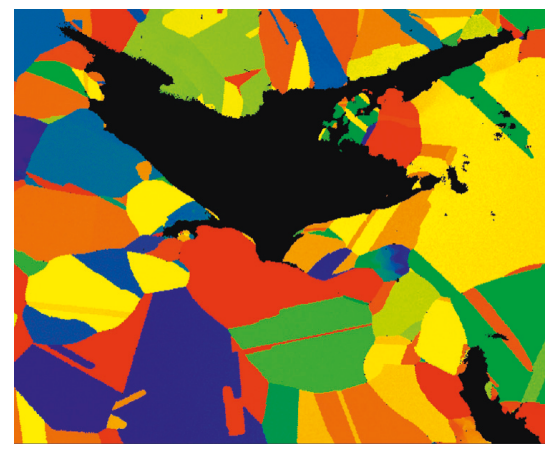

$2.2 \square-3.7$

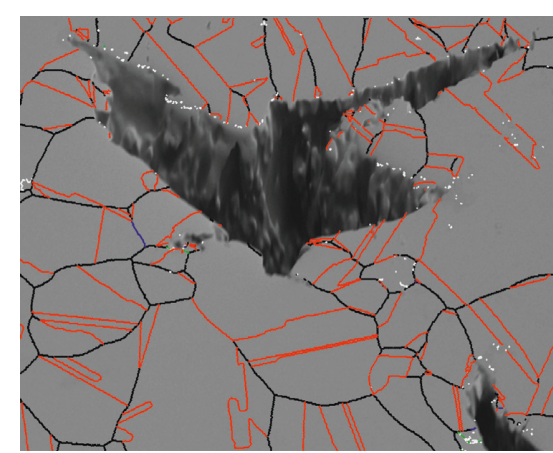

(b)

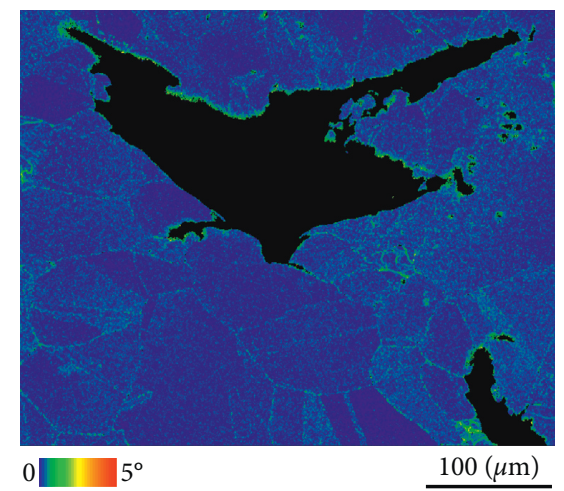

(d)

Figure 6: Microstructure of the longitudinal section near the fracture surface of a specimen tensioned at $1050^{\circ} \mathrm{C}$ and $10^{-4} \cdot \mathrm{s}^{-1}(\mathrm{Region} 1)$. Horizontal direction is the tensile axis. (a) Band contrast image, (b) corresponding SEM map, (c) Taylor factor map, and (d) KAM map.

presence of many TBs in the former and many LAGBs in the latter region.

The area fractions of the different sizes of grains are shown in Figure 2. The average ASTM grain size numbers of the $0.2,0.4,0.6$, and 0.8 reduction specimens were $2.6,3.4$, 5.0 , and 6.2, respectively. The grain refinement effect was remarkable for $18 \mathrm{Mn} 18 \mathrm{Cr} 0.6 \mathrm{~N}$ steel when deformed at $1050^{\circ} \mathrm{C}$ and $10^{-4} \cdot \mathrm{s}^{-1}$.

The microstructure of $18 \mathrm{Mn} 18 \mathrm{Cr} 0.6 \mathrm{~N}$ steel that was compressed at $1150^{\circ} \mathrm{C}$ and $10^{-4} \cdot \mathrm{s}^{-1}$ to strains of $0.2-0.8$ is shown in Figure 3. The magnification is lower than that in Figure 2. In the 0.2 reduction specimen (Figure 3(a)), LAGBs appeared near curved HAGBs. The subgrains were large, and their size was related to the deformation temperature [16]. In the parent grains, twin boundaries maintained their misorientation angle. Several DRX grains appeared near original HAGBs and triple junctions. As the deformation developed, the number of LAGBs increased in the parent grains (Figure $3(\mathrm{~b})$ ). When the strain was increased to 0.6 (Figure 3(c)), the area fraction of the DRX region was larger than that in Figures 3(a) and 3(b). Many LAGBs existed in unrecrystallized grains. Fine DRX grains close to the unrecrystallized grains rarely contained TBs; however, many TBs were formed in the large DRX grains far from the unrecrystallized grains. This phenomenon is similar to that in Figure 2. Because the DRX grain size was large, the necklace features were not obvious in Figure 3(c). In Figure 3 (d) (0.8 reduction), LAGBs appeared in some large recrystallized grains, that is, a new cycle of deformation and DRX began.

The area fractions of the different sizes of grains are shown in Figure 4. The average ASTM grain size numbers of the $0.2,0.4,0.6$, and 0.8 reduction specimens were $2.6,2.5$, 3.2 , and 3.1, respectively. Although some huge grains disappeared after deformation, the grain refinement was not obvious for the strain from 0.2 to 0.8 .

3.2. Fracture Behavior. Figure 5 shows the fracture surface of a specimen tensioned at $1050^{\circ} \mathrm{C}$. The reduction in area was $39 \%$. The fracture surface was rough, and some groves were distributed between the bulges. Dimples or grain surfaces, that is, typical characteristics of ductile fracture or brittle fracture [17], were not found. The inset shows the morphology of the fracture surface at a high magnification. Holes and secondary cracks could be found.

The microstructure of the longitudinal section near the fracture surface of the specimen tensioned at $1050^{\circ} \mathrm{C}$ and $10^{-4} \cdot \mathrm{s}^{-1}$ is shown in Figures 6 and 7.

Figure 6(a) shows a large $\sim 400 \mu \mathrm{m}$ long crack. The crack tips are marked by numbers. In combination with Figure 6(b), it is clear that crack tips 1 and 4 are transgranular. Crack tips 


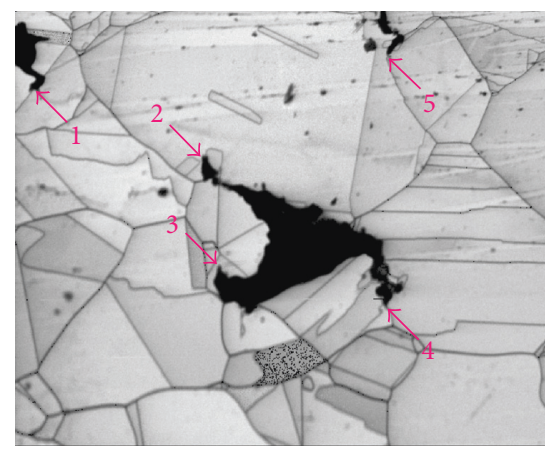

(a)

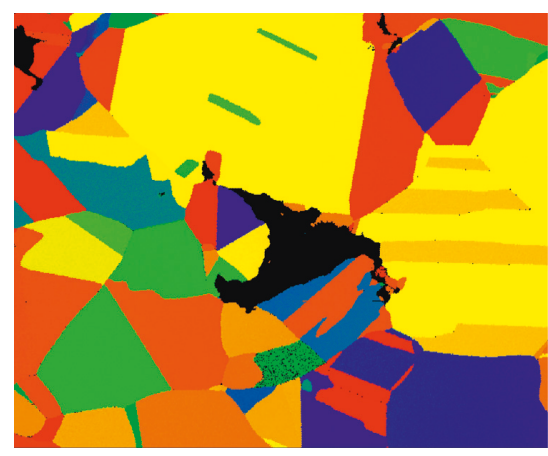

$2.2 \square-3.7$

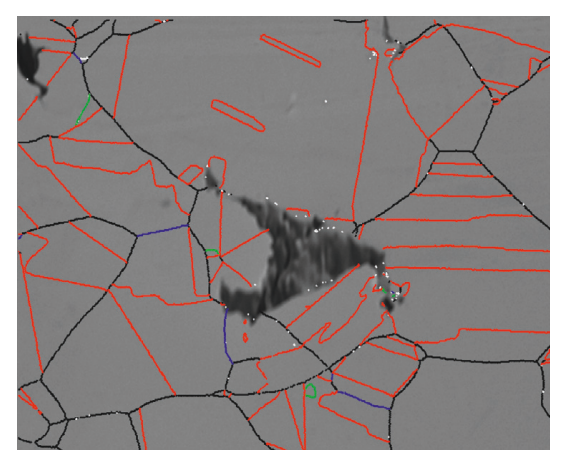

(b)

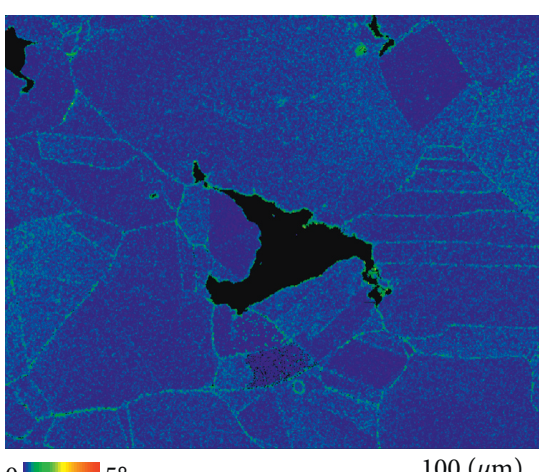

$0 \square 5^{\circ}$

Figure 7: Microstructure of the longitudinal section near the fracture surface of a specimen tensioned at $1050^{\circ} \mathrm{C}$ and $10^{-4} \cdot \mathrm{s}^{-1}(\mathrm{Region} 2)$. (a) Band contrast image, (b) corresponding SEM map, (c) Taylor factor map, and (d) KAM map.

2 and 3 are intergranular. Another crack, with the tip marked 5, was also intergranular. Interestingly, grains near these cracks were almost equiaxed. The TBs in the grain were straight, and no obvious deformation features existed. Figure 6(c) shows that the crack-propagation path was independent of the Taylor factor. In Figure 6(d), the Kernel average misorientation (KAM) values were high at HAGBs and TBs but were low inside the grains.

Figure 7 shows the crack morphology of another region that contains large and small cracks. Crack tip 4 was intergranular, and crack tip 3 was transgranular. Notably, crack tips 1,2, and 5 propagated along the TBs. Crack tip 1 developed from the grain inner and changed its propagation direction along the TB when it intersected the TB. The distributions of the Taylor factor and KAM values were similar to those in Figure 6.

\section{Discussion}

4.1. DRX Mechanism under Very Low Strain-Rate Condition. In metal deformation, a lower strain rate causes a higher strain gradient from HAGBs to the inside of grains [14]. This means that the deformation is located in a very narrow region near the HAGBs, which is termed "GB sliding" $[18,19]$. Owing to the high temperature and low strain rate, dislocations have sufficient time to form dislocation walls and LAGBs $[12,14]$. As the deformation developed, subgrains rotated and their misorientation angle increased. When the misorientation angle exceeded $15^{\circ}$, DRX grains formed. Under further strain, the DRX developed towards the inside of the parent grains. The early formed DRX grains grew and formed internal TBs. Because the deformation and grain growth were simultaneous, LAGBs appeared in these grown DRX grains. The DRX developed first at triple junctions. Because the grains were very large, the number of triple junctions was small, and the effects of triple junctions on the DRX were not as pronounced as those for fine grain materials [20].

On the basis of the above results, a schematic illustration of the nucleation mechanism of the DRX for $18 \mathrm{Mn} 18 \mathrm{Cr} 0.6 \mathrm{~N}$ steel deformed at $10^{-4} \cdot \mathrm{s}^{-1}$ is shown in Figure 8 . The colored lines denote the same boundary types as those described in Figures 1 and 3 .

Figure 9 shows the microstructure in the dashed rectangular region of Figures 1(c) and 3(b) at a high magnification. Subgrains, newly formed DRX grains, and grown DRX grains are marked by blue, black, and red arrows, respectively. The microstructure is consistent with the nucleation mechanism of DRX, as shown in Figure 8.

The DRX nuclei were twin-related $(\Sigma 3)$ to the deformed matrices of copper bicrystals during hot tension at a strain rate of $4.2 \times 10^{-4} \cdot \mathrm{s}^{-1}$ [21]. The results of the copper system 

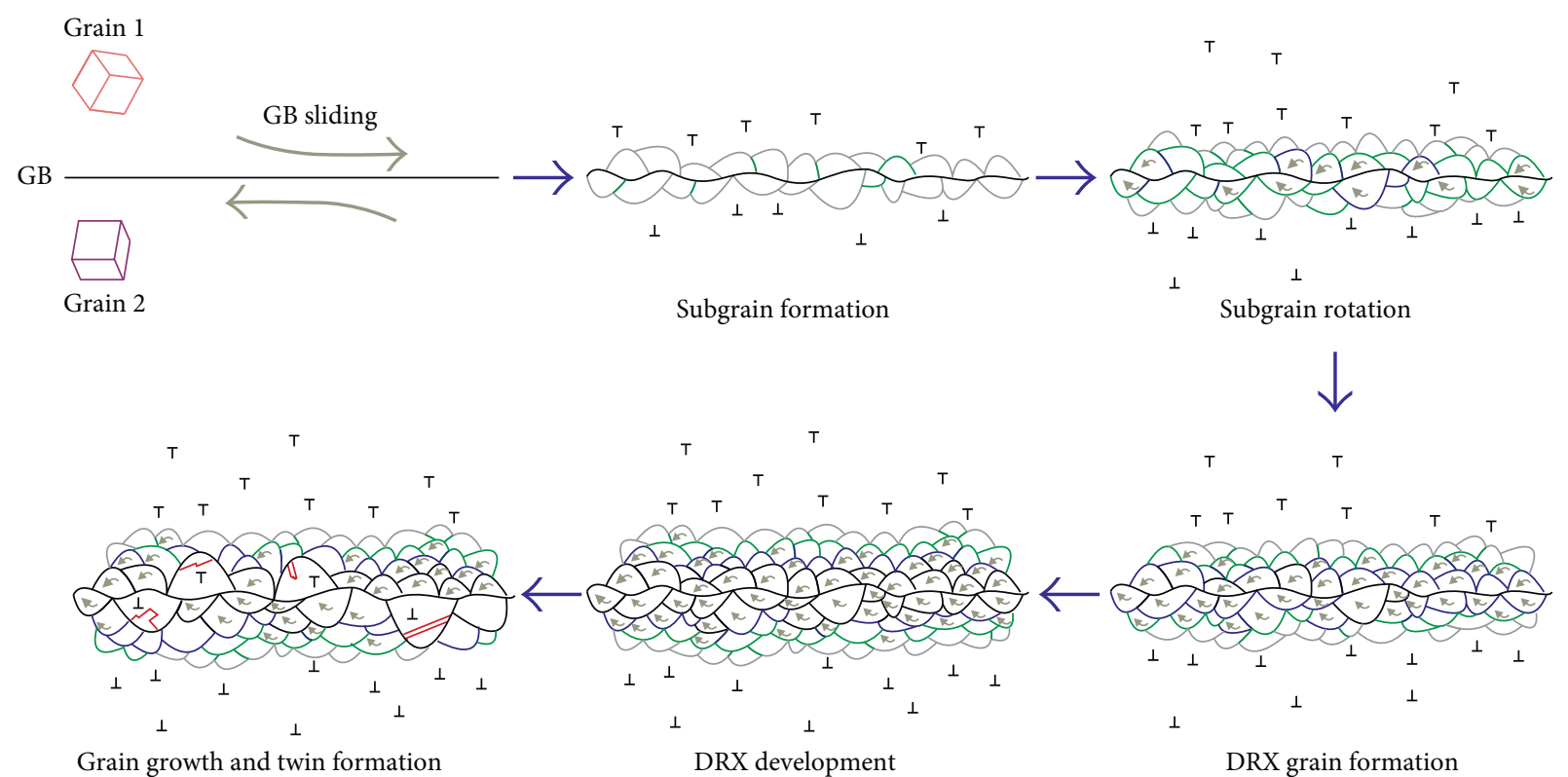

FIGURE 8: Schematic illustration of the nucleation mechanism of DRX for $18 \mathrm{Mn} 18 \mathrm{Cr} 0.6 \mathrm{~N}$ steel compressed at a strain rate of $10^{-4} \cdot \mathrm{s}^{-1}$.

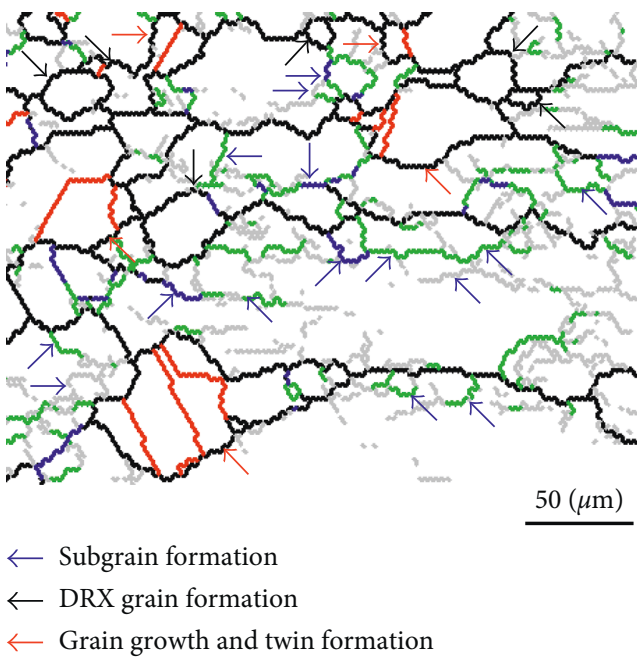

(a)

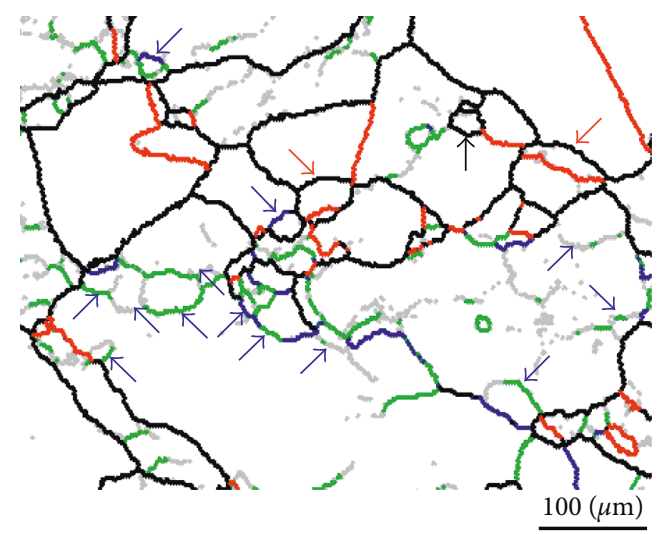

$\leftarrow$ Subgrain formation

$\leftarrow$ DRX grain formation

$\leftarrow$ Grain growth and twin formation

(b)

FIgURE 9: Microstructure in the region enclosed by the dashed rectangle in (a) Figure 1(c) and (b) Figure 3(b) at higher magnifications.

were different from those of our study, in terms of low-angle misorientation between the DRX nuclei and matrices (Figures 1 and 3). The DRX nucleation mechanisms relied on bulging HAGBs for $800 \mathrm{H}$ stainless steel [22] and 617B nickel alloy [13] deformed at $10^{-3} \cdot \mathrm{s}^{-1}$. However, bulging HAGBs were not necessary in the nucleation of DRX in this study (Figure 9). Here, the nucleation mechanism of DRX was similar to that under low deformation temperature conditions [23]. In this study, a very low strain rate, high deformation temperature, and large grain size promoted the formation of LAGBs and subgrains. Figure 10 shows the TEM result of the specimen that is compressed at $1050^{\circ} \mathrm{C}$ and $10^{-4} \cdot \mathrm{s}^{-1}$ to a strain rate of 0.2 . Dislocations entangled LAGBs and subgrains. The nucleation mechanisms of DRX are complex and depend on many factors, such as the deformation temperature [23], strain rate [14, 16], grain size [24], precipitation [25], and stacking fault energy [16, 26]. Further studies are required to clarify the effects of these factors.

4.2. Cracking Mechanisms under Very Low Strain-Rate Condition. From the data in Figures 6 and 7, three paths for crack propagation exist, namely, grain inner, grain boundary, and TBs. As mentioned above, under low strainrate conditions, grain boundary sliding occurred. This means that the grain is likely to rotate under tension. Because the grains are large, cracks formed easily when the 


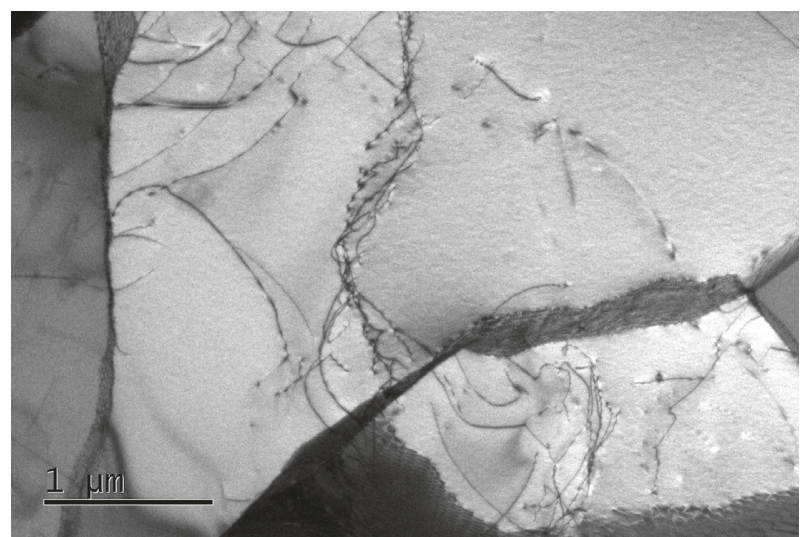

Figure 10: TEM microstructure of $18 \mathrm{Mn} 18 \mathrm{Cr} 0.6 \mathrm{~N}$ steel compressed at $1050^{\circ} \mathrm{C}$ and $10^{-4} \cdot \mathrm{s}^{-1}$ to 0.2 .

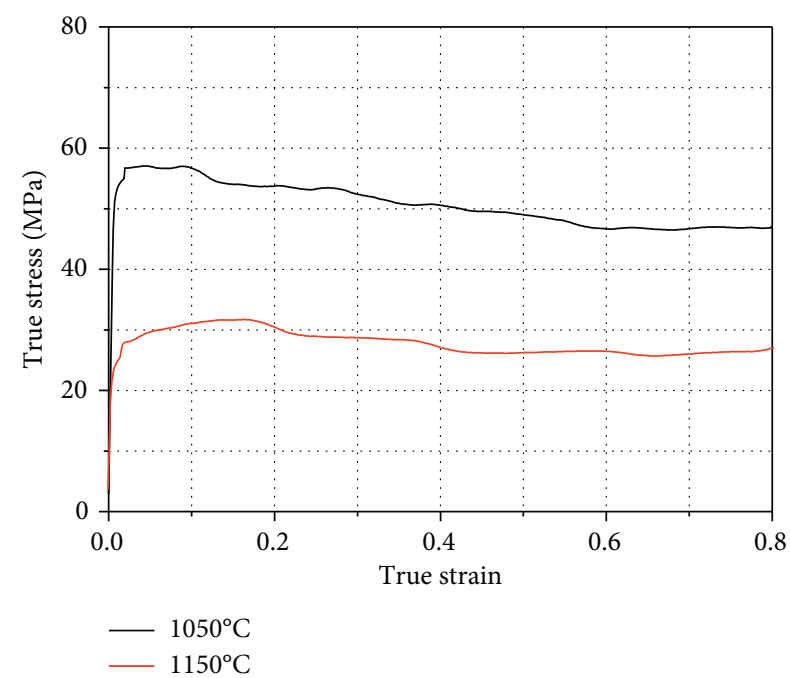

Figure 11: Flow curves of $18 \mathrm{Mn} 18 \mathrm{Cr} 0.6 \mathrm{~N}$ steel deformed at $10^{-4} \cdot \mathrm{s}^{-1}$.

deformation could not be accommodated between grains. Cracks propagated along the HAGBs and TBs as the KAM values in these regions were high. Transgranular cracking can be explained by Wang et al. [14]. Owing to the many propagation paths for cracking, the reduction in area in this study is much lower than that at $10^{-3} \cdot \mathrm{s}^{-1}$ [14]. Because the grains rotate readily and the extent of deformation is small inside the grains, the effect of Taylor factor distribution on cracking is not as important as that under high strain-rate conditions [17].

The tensioned microstructure was significantly different from the compressed microstructure. The most obvious difference was that more LAGBs existed inside grains in the latter case. This result can be explained as follows. First, different deformation types induce different deformed microstructures, [27] and the recrystallized microstructure also presents differences [28]. Second, the LAGBs are a type of defect that accumulates energy. During tension, the deformation energy is released by cracking. Third, when necking appeared on the tensile specimen, the stress state was under triaxial tension, which accelerated the diffusion and movement of defects to the GBs and TBs. Owing to the equipment limitations, a tensile test at $1150^{\circ} \mathrm{C}$ was not conducted but will be studied in future using a more powerful machine.

4.3. Hot Forging of Superheavy Forgings. In the hot forging of superheavy forgings, heating over a long time is required for temperature homogenization [29]. The grain size is large, especially at the surface layer of the ingot. In addition, large ingots feature a high deformation resistance, especially during upsetting. Therefore, the large initial grain size and low strain rate are the main deformation features of superheavy forgings. The results indicate that the grain refinement is not obvious at $1150^{\circ} \mathrm{C}$. A lowering of the deformation temperature can decrease the grain size, but the deformation stress increases considerably. The deformation stress at $1050^{\circ} \mathrm{C}$ was almost twice that at $1150^{\circ} \mathrm{C}$, as shown in Figure 11.

It is suggested that the upsetting ratio should not be too large. A large reduction increases the deformation resistance in the upsetting process and in the ensuing stretching process. To satisfy the total deformation ratio, we recommend alternate deformations of upsetting and stretching with a medium amount of forging strain. Furthermore, the ingot dimensions should be tailor designed, that is, with a larger height and smaller diameter. Macrosegregation and shrinkage porosity are reduced in ingots with this shape. Therefore, the demanded total deformation ratio is lowered, especially for monoblock low-pressure rotors.

As mentioned in [3] and [4], the manufacture of superheavy forgings is pushing the limits of the current freeforging industry. To refine the grain size and to improve hot ductility, the deformation rate must be improved. Thus, in future, larger hydraulic presses should be developed.

\section{Conclusions}

Microstructure evolution and surface cracking behaviors were investigated through compression and tensile tests at a strain rate of $10^{-4} \cdot \mathrm{s}^{-1}$. The domain nucleation of DRX is LAGB formation and subgrain rotation, which is independent of the bulging of original HAGBs and twinning. Twins were formed during the growth of DRX grains. The grain refinement was not obvious at $1150^{\circ} \mathrm{C}$. A lowering of the deformation temperature to $1050^{\circ} \mathrm{C}$ resulted in a fine grain structure; however, the resulting stress was twice as large. Crack-propagation paths included HAGBs, TBs, and the inside of grains, in that sequence. For superheavy forgings, the ingot should have a larger height and a smaller diameter. During the forging process, the use of alternate deformations of upsetting and stretching with a medium strain is recommended.

\section{Conflicts of Interest}

The authors declare that there are no conflicts of interest. 


\section{Acknowledgments}

The authors gratefully acknowledge the financial support of the project from the National Natural Science Foundation of China (no. 51505416), the Natural Science Foundation-Steel and Iron Foundation of Hebei Province (no. E2017203041), the Post-Doctoral Research Project of Hebei Province (no. B2016003029), and the Foundation for Young Scholars in Yanshan University (no. 14LGA004).

\section{References}

[1] Y. Tanaka and I. Sato, "Development of high purity large forgings for nuclear power plants," Journal of Nuclear Materials, vol. 417, no. 1-3, pp. 854-859, 2011.

[2] B. Z. Wang, K. Q. Liu, Y. Liu, W. H. Zhang, and D. L. Zhao, "Development of mono-bloc forging for CAP1400 reactor pressure vessel," in Proceedings of the Energy Materials 2014, pp. 443-450, Xi'an, Shaanxi Province, China, November 2014.

[3] X. L. Jiang, "Research and application of extreme manufacturing technology of 600 tonner low segregation and high purity heavy alloy ingot," Heavy Casting and Forging, vol. 5, pp. 15-23, 2013, in Chinese.

[4] J. Y. Jin, S. T. Rui, and Q. Wang, "The anatomy of AP100 mono-block low pressure rotor forging," in Proceedings of the Energy Materials 2014, pp. 509-513, Xi'an, Shaanxi Province, China, 2014.

[5] G. E. Dieter, H. A. Kuhn, and S. L. Semiatin, Handbook of Workability and Process Design, ASM International, Materials Park, OH, USA, 1st edition, 2003.

[6] F. Chen, Z. S. Cui, and S. J. Chen, "Recrystallization of $30 \mathrm{Cr} 2 \mathrm{Ni} 4 \mathrm{MoV}$ ultra-super-critical rotor steel during hot deformation. Part I: dynamic recrystallization," Materials Science and Engineering A, vol. 528, no. 15, pp. 5073-5080, 2011.

[7] Z. H. Wang, W. T. Fu, B. Z. Wang, W. H. Zhang, Z. Q. Lv, and P. Jiang, "Study on hot deformation characteristics of $12 \%$ Cr ultra-super-critical rotor steel using processing maps and Zener-Hollomon parameter," Materials Characterization, vol. 61, no. 1, pp. 25-30, 2010.

[8] M. W. Guo, Z. H. Wang, Z. A. Zhou, S. H. Sun, and W. T. Fu, "Effect of nitrogen content on hot deformation behavior and grain growth in nuclear grade $316 \mathrm{LN}$ stainless steel," Advances in Materials Science and Engineering, vol. 2015, Article ID 427945, 8 pages, 2015.

[9] X. W. Duan and J. S. Liu, "Research on damage evolution and damage model of 316LN steel during forging," Materials Science and Engineering A, vol. 588, pp. 265-271, 2013.

[10] J. Ping, F. Wantang, W. Zhenhua, B. Xinghong, Z. ZhaoXichun, and L. V. Zhiqing, "Hot deformation behavior of an $8 \%$ Cr roller steel," Journal of Materials Science, vol. 46, no. 13, pp. 4654-4659, 2011.

[11] Z. H. Wang, S. H. Sun, Z. P. Shi, B. Wang, and W. T. Fu, "Hot ductility behavior of an 8 Pct roller steel," Metallurgical and Materials Transactions A, vol. 46, no. 4, pp. 1767-1775, 2015.

[12] A. Dehghan-Manshadi and P. D. Hodgson, "Dynamic recrystallization of austenitic stainless steel under multiple peak flow behaviours," ISIJ International, vol. 47, no. 12, pp. 1799-1803, 2007.

[13] H. Jiang, J. X. Dong, M. C. Zhang, and Z. H. Yao, "Evolution of twins and substructures during low strain rate hot deformation and contribution to dynamic recrystallization in alloy 617B," Materials Science and Engineering A, vol. 649, pp. 369-391, 2016.
[14] Z. H. Wang, Q. Meng, M. G. Qu, Z. A. Zhou, B. Wang, and W. T. Fu, "Effect of stain rate on hot ductility behavior of a high nitrogen Cr-Mn austenitic steel," Metallurgical and Materials Transactions A, vol. 47, no. 3, pp. 1268-1279, 2016.

[15] D. Ponge and G. Gottstein, "Necklace formation during dynamic recrystallization: mechanisms and impact on flow behavior," Acta Metallurgica, vol. 46, no. 1, pp. 69-90, 1998.

[16] T. Sakai, A. Belyakov, R. Kaibyshev, H. Miura, and J. J. Jonas, "Dynamic and post-dynamic recrystallization under hot, cold and severe plastic deformation conditions," Progress in $\mathrm{Ma}$ terials Science, vol. 60, pp. 130-207, 2014.

[17] Z. H. Wang, S. H. Sun, B. Wang, Z. P. Shi, and W. T. Fu, "Importance and role of grain size in free surface cracking prediction of heavy forgings," Materials Science and Engineering A, vol. 625, pp. 321-330, 2015.

[18] M. Jafari and A. Najafizadeh, "Correlation between ZenerHollomon parameter and necklace DRX during hot deformation of 316 stainless steel," Materials Science and Engineering $A$, vol. 501, no. 1-2, pp. 16-25, 2009.

[19] C. Rehrl, S. Kleber, O. Rent, and R. Pippan, "Effect of grain size in compression deformation on the microstructural evolution of an austenitic stainless steel," Materials Science and Engineering A, vol. 540, pp. 55-62, 2012.

[20] M. El Wahabi, L. Gavard, F. Montheillet, J. M. Cabrera, and J. M. Prado, "Effect of initial grain size on dynamic recrystallization in high purity austenitic stainless steel," Acta Materialia, vol. 53, no. 17, pp. 4605-4612, 2005.

[21] H. Miura, T. Sakai, R. Mogawa, and J. J. Jonas, "Nucleation of dynamic recrystallization and variant selection in copper bicrystals," Philosophical Magazine, vol. 87, no. 27, pp. 4197-4209, 2007.

[22] K. Graetz, C. Miessen, and G. Gottstein, "Analysis of steadystate dynamic recrystallization," Acta Materialia, vol. 67, pp. 58-66, 2014.

[23] N. Dudova, A. Belyakov, T. Sakai, and R. Kaibyshev, "Dynamic recrystallization mechanisms operating in a Ni-20\% $\mathrm{Cr}$ alloy under hot-to-warm working," Acta Materialia, vol. 58, no. 10 , pp. $3624-3632,2010$.

[24] Z. H. Wang, S. H. B. Wang, Z. P. Shi, R. H. Zhang, and W. T. Fu, "Effect of grain size on dynamic recrystallization and hot-ductility behaviors in high-nitrogen CrMn austenitic stainless steel," Metallurgical and Materials Transactions A, vol. 45, no. 8, pp. 3631-3639, 2014.

[25] S. Y. Park and W. J. Kim, "Difference in the hot compression behavior and processing maps between the as-cast and homogenized Al-Zn-Mg-Cu (7075) alloys," Journal of Materials Science and Technology, vol. 32, no. 7, pp. 660-670, 2016.

[26] R. D. Doherty, D. A. Hughes, F. J. Humphreys et al., "Current issues in recrystallization: a review," Materials Science and Engineering A, vol. 238, no. 2, pp. 219-274, 1997.

[27] F. J. Humphreys and M. Hatherly, Recrystallization and Related Annealing Phenomena, pp. 14-15, Elsevier, Oxford, UK, 2nd edition, 2004.

[28] J. J. Qi, B. Y. Huang, Z. H. Wang, H. Ding, J. L. Xi, and $\mathrm{W}$. T. Fu, "Dependence of corrosion resistance on grain boundary characteristics in a high nitrogen CrMn austenitic stainless steel," Journal of Materials Science and Technology, 2017. in press.

[29] Y. L. Guo, E. H. Han, and J. Q. Wang, "Effects of forging and heat treatments on the microstructure and oxidation behavior of 316LN stainless steel in high temperature water," Journal of Materials Science and Technology, vol. 31, pp. 403-412, 2015. 


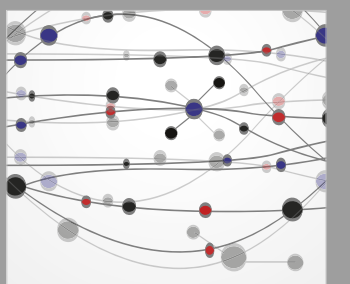

The Scientific World Journal
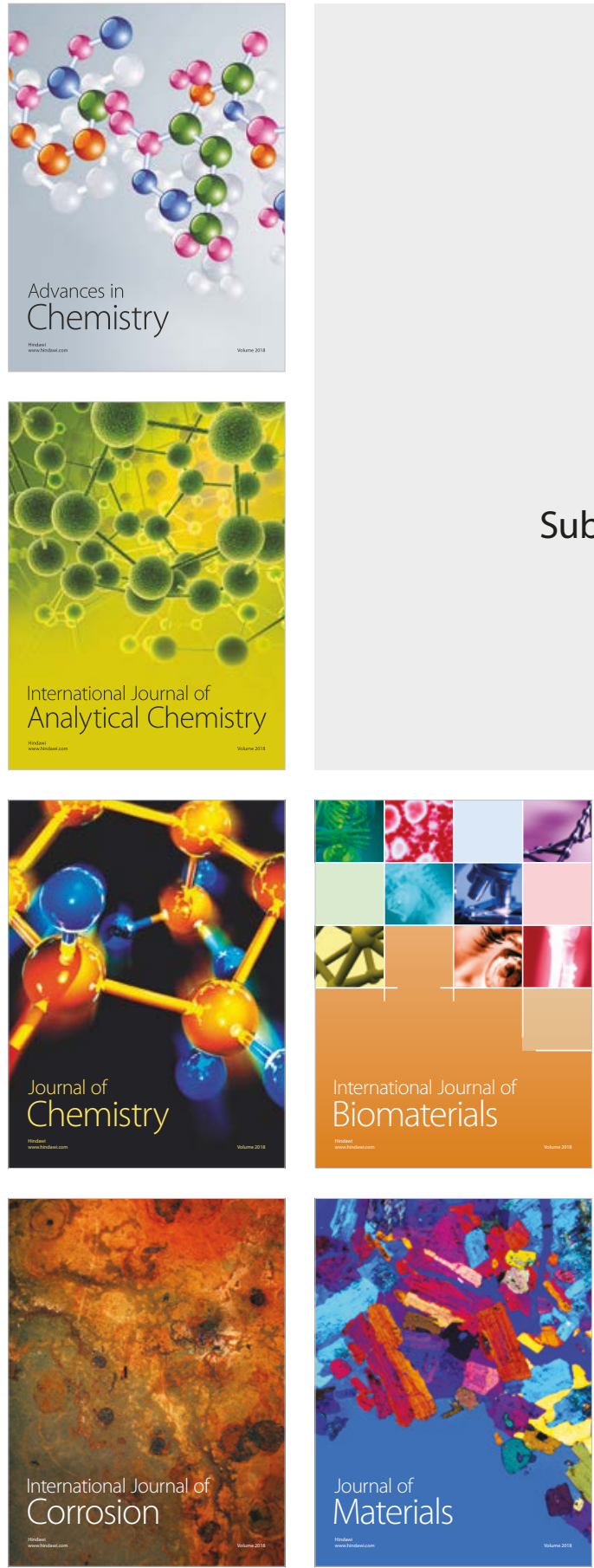

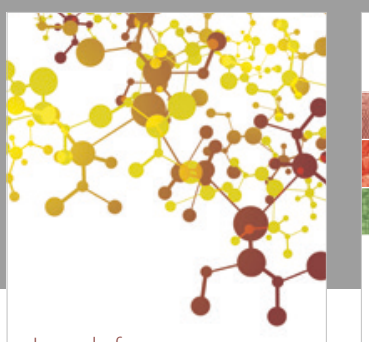

Journal of

Applied Chemistry
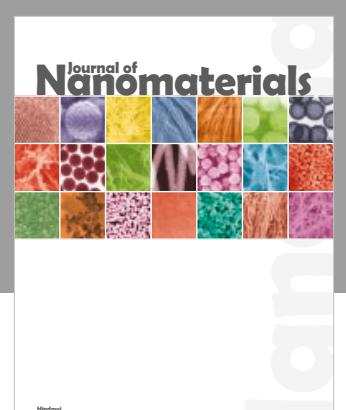

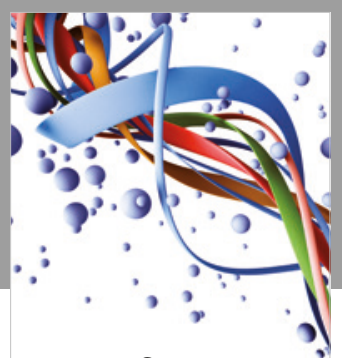

Scientifica

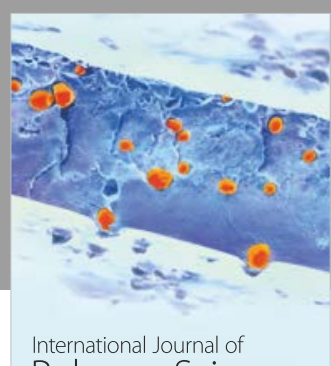

Polymer Science

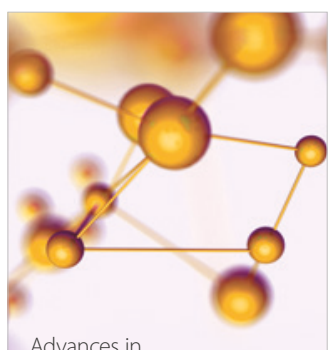

Physical Chemistry
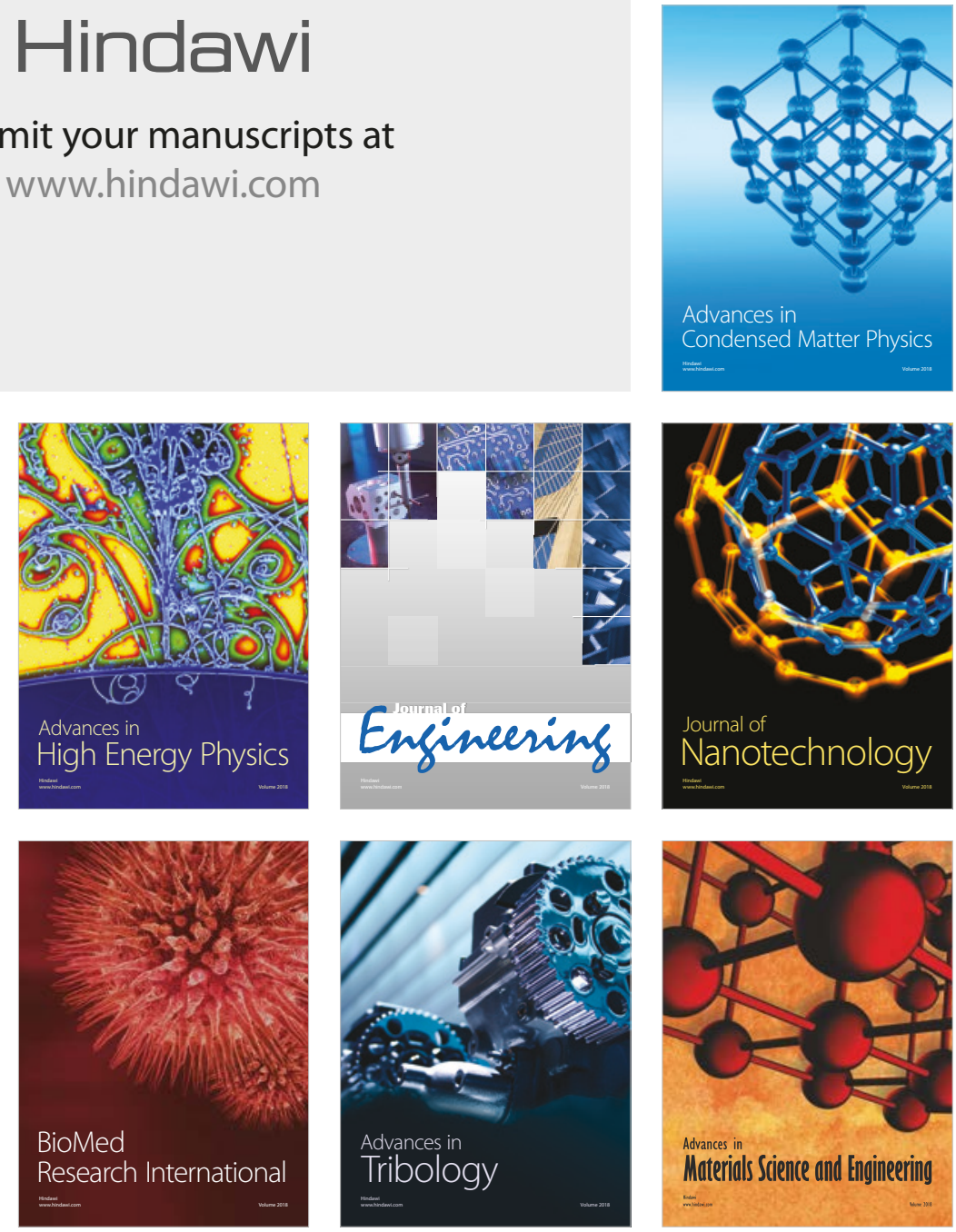